\title{
Efeito do ácido tranexâmico associado à cola de fibrina sobre o reparo ósseo: estudo histológico em ratos
}

Effect of tranexamic acid associated with fibrin glue in bone repair: histologic study in rats

Efecto del ácido tranexámico asociado con adhesivo de fibrina en la reparación ósea: estudio histológico en ratos

\author{
Maria Cristina Rosifini ALVES REZENDE ${ }^{1}$ \\ Luiz Guilherme FIORIN ${ }^{1}$ \\ Marina Tolomei Sandoval CURY ${ }^{1}$ \\ Vanessa Mosca GONÇALVES ${ }^{1}$ \\ Luis Guilherme Rosifini ALVES REZENDE ${ }^{2}$ \\ Cristiane Mayumi WADA ${ }^{3}$ \\ André Luiz Reis RANGEL ${ }^{4}$ \\ Ana Laura Rosifini ALVES REZENDE ${ }^{5}$ \\ Ana Paula Rosifini ALVES CLARO ${ }^{4}$
}

${ }^{\text {I}}$ Faculdade de Odontologia de Araçatuba, UNESP-Univ. Estadual Paulista, Araçatuba-SP, Brasil

${ }^{2}$ Faculdade de Medicina, UNAERP-Universidade de Ribeirão Preto, Ribeirão Preto-SP, Brasil

${ }^{3}$ POSMAT, Faculdade de Ciências de Bauru, UNESP-Univ. Estadual Paulista, Bauru-SP, Brasil

${ }^{4}$ Faculdade de Engenharia de Guaratinguetá, UNESP-Univ. Estadual Paulista, Guaratinguetá-SP, Brasil

${ }^{5}$ Faculdade de Medicina, PUCCAMP-Pontifícia Universidade Católica de Campinas, Campinas-SP, Brasil

\section{Resumo}

O processo de reparação óssea é controlado por mecanismos moleculares complexos que envolvem fatores sistêmicos e locais. Os adesivos fibrínicos, também conhecidos como selantes de fibrina ou cola de fibrina são produtos não citotóxicos, oriundos de proteínas do plasma humano, que mimetizam a via final da rede de coagulação. Os agentes antifibrinolíticos, tais como o ácido tranexâmico, inibem a fibrinólise e, conseqüentemente, impedem ou diminuem a formação dos produtos de degradação da fibrina e do fibrinogênio. O propósito deste trabalho foi avaliar histologicamente em ratos o efeito do ácido tranexâmico associado à cola de fibrina sobre o reparo ósseo. O experimento utilizou 60 (n=5) ratos machos em grupos assim constituídos: GI:Controle, GII: cola de fibrina, GIII:ácido tranexâmico e GIV: cola de fibrina/ácido tranexâmico. Defeitos ósseos (2.5mm de diâmetro) foram criados nas tíbias direitas. Os animais foram eutanasiados aos 7,14 e 30 dias pósoperatórios e as peças processadas em hematoxilina e eosina. Os resultados mostraram aos 7 dias pós-operatórios cavidade cirúrgica preenchida por tecido conjuntivo denso, rico em fibroblastos, permeado por delicadas trabéculas ósseas neoformadas, em percentual de 7080\% para GI, GII e GIII e $94.8 \%$ para GIV. Aos 14 dias pós-operatórios tecido ósseo neoformado foi encontrado entre 75-85\% para GI, GII e GIII e em percentual acima de 95\% para GIV. Aos 30 dias pós-operatórios GI e GIV apresentaram 95-100\% de tecido ósseo maduro; GII e GIII em percentual próximo a 80-90\%. Com base nos resultados obtidos e metodologia empregada conclui-se que a associação cola de fibrina/ácido tranexâmico tem ação positiva sobre a reparação óssea.

Descritores: Cicatrização; Adesivo Tecidual de Fibrina; Ácido Tranexâmico.

\section{Abstract}

The bone repair process is controlled by complex molecular mechanisms that involve systemic and local factors. Fibrin glue is derived from human plasma and mimics the final pathway of coagulation network. Tranexamic acid inhibits fibrinolysis and prevents or decreases the formation of degradation products of fibrin and fibrinogen. The purpose of this study was to evaluate histologically in rats the effect of tranexamic acid associated with the fibrin glue on bone healing.

The experiment used $60(\mathrm{n}=5)$ male rats in: GI: Control, GII: fibrin glue, GIII tranexamic acid and GIV /fibrin glue/tranexamic acid. Bone defect $(2.5 \mathrm{~mm}$ diameter) was created in right tibia. The animals were euthanized at 7,14 and 30 days postoperatively, and the pieces were processed with hematoxylin and eosin. The results showed at 7 days post-operative surgical cavity filled with dense connective tissue rich in fibroblasts, permeated by delicate neoformed bone trabeculae in percentage of 70-80\% for GI, GII and GIII and GIV to $94.8 \%$. At 14 days post-operative newly formed bone was found between $75-85 \%$ for GI, GII and GIII and percentage above $95 \%$ for GIV. At 30 days postoperative GI and GIV showed $95-100 \%$ of mature bone tissue; GII and GIII in percentage close to 80-90\%. Based on the results and methodology is concluded that fibrin / tranexamic acid glue association has positive action on bone repair.

Descriptors: Wound Healing; Fibrin Tissue Adhesive; Tranexamic Acid.

\section{Resumen}

El proceso de reparación ósea es controlado por mecanismos moleculares complejos que implican los factores sistémicos y locales. El adhesivo de fibrina se deriva de plasma humano e imita la vía final de la red de la coagulación. El ácido tranexámico inhibe la fibrinólisis y evita o disminuye la formación de productos de degradación de fibrina y fibrinógeno. El propósito de este estudio fue evaluar histológicamente en ratos el efecto del ácido tranexámico asociado con el adhesivo de fibrina en la cicatrización del hueso. El experimento utilizó $60(\mathrm{n}=5)$ ratos macho: GI: controlo, GII: adhesivo de fibrina, GIII: ácido tranexámico y GIV ácido tranexámico / adhesivo de fibrina. Defecto óseo (2,5 mm de diámetro) fue creado en la tibia derecha. Los animales se sacrificaron a los 7,14 y 30 días después de la operación y el espécimen se procesó con hematoxilina y eosina. Los resultados mostraron en la cavidad quirúrgica 7 días después de la operación llena de tejido conectivo denso rico en fibroblastos, permeada por delicado trabéculas de hueso neoformado en porcentaje de 70-80\% para GI, GII y GIII y GIV a 94,8\%. A los 14 días se encontró el hueso después de la operación recién formado entre 75-85\% para GI, GII y GIII y porcentaje por encima del 95\% para GIV. A los 30 días GI postoperatorio y GIV mostraron 95-100\% de tejido óseo maduro; GII y GIII en porcentaje cercano al $80-90 \%$. Con base en los resultados y la metodología se concluye que el asociación adhesivo de fibrina /ácido tranexámico tiene una acción positiva en la reparación ósea.

Descriptores: Cicatrización de Heridas; Adhesivo de Tejido de Fibrina; Ácido Tranexámico.

\section{INTRODUÇÃO}

O processo de reparação óssea é controlado por mecanismos moleculares complexos que envolvem fatores sistêmicos e locais. Os adesivos fibrínicos, também conhecidos como selantes de fibrina ou cola de fibrina são produtos não citotóxicos, oriundos de proteínas do plasma humano, que mimetizam a via final da rede de coagulação ${ }^{1-5}$. Nesses produtos, o fibrinogênio é proteolicamente clivado e convertido em polímeros de fibrina pela ação da trombina. Assim, quando o Fator XIII é ativado pela trombina na presença de cálcio, reage com os polímeros de fibrina resultando em coágulo 
estável, insolúvel e semelhante ao coágulo fisiológico ${ }^{1}$. A lise prematura do coágulo de fibrina formado é impedida pela presença de aprotinina, potente inibidor da fibrinólise $\mathrm{e}^{1,2,6}$.

O selante de fibrina é tolerado de forma excelente pelo organismo e raríssimos casos de eventos adversos têm sido relatados em pacientes ${ }^{1,7}$. Estes materiais são utilizados em diferentes campos cirúrgicos como agentes hemostáticos e indutores de processo de cicatrização $o^{2,8}$. O material é considerado scaffold por vários autores, em razão de servir como arcabouço e /ou ancoragem para fixação e crescimento celular $^{9-11}$.

A quebra da fibrina pela ação da plasmina é a base da fibrinólise $e^{2,12}$. Durante a coagulação sanguínea, após a formação inicial do botão plaquetário, a rede de fibrina inicia seu papel estabilizador sobre o coágulo primário. Essa fase é conhecida pela participação de duas vias: via intrínseca (ou via do fator de contato) e via extrínseca (ou via do fator tecidual), embora ocorra a participação de fatores nas duas vias simultaneamente. Nota-se que in vitro a ativação da coagulação pode ocorrer por qualquer uma dessas vias. A via extrínseca é ativada quando o fato tecidual é exposto após à lesão vascular e o trauma. Nessa fase participam o fator $\mathrm{V}$ e o fator $\mathrm{X}$ e é chamada de via comum ou fase final da cascata de coagulação, cujo objetivo é formar trombina. Atualmente é aceito que o início da coagulação ocorre quando o fator tecidual é exposto ao espaço intravascular após a lesão do endotélio/trauma ou pela liberação de citocinas. O fator tecidual liga-se ao fator VII ativado (Fator VIIa) que corresponde a 1\% de todo fator VII circulante. O complexo fator tecidual/fator VIIa ativará os fatores IX e X, o qual, por sua vez, ativará o Fator $\mathrm{V}$, formando um complexo que tem como resultado final a formação de pequena quantidade de trombina. A trombina formada, por sua vez, será é capaz de ativar plaquetas, fator VIII, fator V e fator XI. A superfície da plaqueta ativada servirá como local onde o complexo Fator VIIIa/Fator IXa ativará o fator X com eficiência 50 vezes maior que o complexo Fator Tecidual/Fator VIIa. O Fator Xa, por sua irá se ligar ao Fator Va em outro local da superfície plaquetária formando o complexo protrombinase, que será capaz de formar grandes quantidades de trombina a partir do Fator Xa. A trombina, por sua vez, converterá fibrinogênio em fibrina, promovendo a ativação plaquetária e ativando o fator XIII, responsável pela polimerização da fibrina e da maior resistência do coágulo. Outra via de coagulação sanguínea envolve o fator XII, cininogênio de alto peso molecular, precalicreína e fator XI com posterior ativação do fator IX. O papel dessa via ainda não está bem esclarecido, já que a deficiência do fator XII não provoca alteração na coagulação. No entanto, a deficiência do fator XI pode ocasionar episódios moderados de sangramento ${ }^{13}$. Para Roberts et al. ${ }^{14}$ a deficiência do fator XI ocasiona alterações da coagulação de pequeno significado clínica.

A fibrinólise se antagoniza à coagulação. Participam dela o plasminogênio e o ativador tecidual do plasminogênio (t-PA), protease que transforma o plasminogênio em plasmina. Por ser uma enzima proteolítica de amplo espectro, a plasmina digere fibrina, fibrinogênio e a maioria dos fatores e cofatores de coagulação ${ }^{15}$.

A estabilização da fibrina se dá pela formação de ligações cruzadas sob ação do fator XIII. A lise do coágulo antes da formação das ligações cruzadas origina produtos de degradação da fibrina e do fibrinogênio (PDF) enquanto a lise do coágulo após a estabilização da fibrina origina D-dímeros ${ }^{2,6,16}$. Os antifibrinolíticos inibem a fibrinólise e, conseqüentemente, impedem ou diminuem a formação dos produtos de degradação da fibrina e do fibrinogênio, que têm ação deletéria sobre a função plaquetária ${ }^{17}$. Além disso, os antifibrinolíticos também diminuem a conversão do plasminogênio em plasmina, os quais têm atividade proteolítica nos receptores plaquetários.

Atualmente, são três os agentes antifibrinolíticos mais empregados na área da cirurgia médica e odontológica: aprotinina, inibidor de proteases séricas de amplo espectro, a aprotinina, e dois análogos do aminoácido lisina, com fórmulas estruturais semelhantes: ácido tranexâmico e ácido épsilon aminocapróico. $\mathrm{O}$ ácido tranexâmico é de seis a dez vezes mais potente que o ácido épsilon aminocapróico $^{18-20}$, além de apresentar maior afinidade pelo plasminogênio, maior atividade antifibrinolítica e maior tempo de ação.

A atividade antifibrinolítica do ácido tranexâmico se deve ao bloqueio quase completo da interação entre o ativador tecidual do plasminogênio, o plasminogênio e o monômero de fibrina em virtude da alta afinidade pelos locais de ligação da lisina do plasminogênio $^{19}$. Esse processo inibe ou retarda a fibrinólise porque a plasmina, embora formada, não consegue se ligar à fibrina, já que ocorre competição entre a lisina e o ácido tranexâmico.

O ácido tranexâmico na concentração de 5\% é algumas vezes prescrito para lavagem da cavidade bucal após exodontias ou na forma de pasta. $\mathrm{Na}$ área médica autores têm demonstrado que seu uso tópico diminui a necessidade de transfusões em cirurgias de artroplastia de fêmur ${ }^{21}$. A substância é livremente solúvel em água. Uma solução a $5 \%$ possui $\mathrm{pH}$ entre 6,5 e 8. Formulação líquida do ácido tranexâmico é disponibilizada comercialmente em alguns países, mas não no Brasil. Para o preparo da solução um comprimido de $500 \mathrm{mg}$ triturado é misturado a soro fisiológico e filtrados os excipientes insolúveis para resultar em solução límpida. Para o preparo da pasta 
um comprimido de 500mg deve ser macerado e colocado em gaze ou mesmo diretamente sobre a ferida cirúrgica ${ }^{22}$.

O propósito deste trabalho foi avaliar histologicamente em ratos o efeito do ácido tranexâmico associado à cola de fibrina sobre $\mathrm{o}$ reparo ósseo.

\section{MATERIAL E MÉTODO}

O experimento utilizou $60 \quad(n=5)$ ratos machos em grupos assim constituídos: GI: Controle, GII: cola de fibrina, GIII:ácido tranexâmico e GIV: cola de fibrina/ácido tranexâmico. Sob anestesia geral os animais receberam tricotomia em suas patas traseiras direitas, seguida de incisão, divulsão dos tecidos, criação de defeito ósseo $(2.5 \mathrm{~mm}$ de diâmetro) em tíbia, tratamento pertinente ao grupo e sutura com fio 4.0. Em GIII e GIV as cavidades ósseas foram preenchidas com ácido tranexâmico em solução saturada a $5 \%$. Em GII o preenchimento foi realizado com cola de fibrina e em GIV com a associação cola de fibrina/ácido tranexâmico.

A cola de fibrina foi prepara seguindo-se protocolo estabelecido pelo fabricante. A solução saturada de ácido tranexâmico por meio de cálculo estequiométrico sendo o solvente soro fisiológico estéril. O tamanho da amostra (número de animais) foi baseado em relações matemáticas entre o valor do efeito estudado (a diferença biologicamente significante), o desvio padrão (obtido no piloto), o nível de significância $(0,05 \%)$ e o poder da prova (80\%-90\%), de acordo com Scheibe ${ }^{23}$. Os animais foram eutanasiados aos 7,14 e 30 dias pósoperatórios e as peças processadas em hematoxilina e eosina (cortes com 6 micrometros de espessura) para estudo histomorfométrico. A pesquisa foi aprovada pela Comissão de Ética no Uso de Animal da Faculdade de Odontologia de Araçatuba, Unesp (CEUA/FOA/UNESP 00265/12).

\section{RESULTADOS}

Observou-se aos 7 dias pós-operatórios cavidade cirúrgica preenchida por tecido conjuntivo denso, rico em fibroblastos, permeado por delicadas trabéculas ósseas neoformadas, em percentual de 70$80 \%$ para GI, GII e GIII e $94.8 \%$ para GIV. Aos 14 dias pós-operatórios tecido ósseo neoformado foi encontrado entre $75-85 \%$ para GI, GII e GIII e em percentual acima de $95 \%$ para GIV. Aos 30 dias pósoperatórios GI e GIV apresentaram 95-100\% de tecido ósseo maduro; GII e GIII em percentual próximo a $80-90 \%$ (Figuras 1 a 4 ).

\section{DISCUSSÃO}

$\mathrm{O}$ equilíbrio dos mecanismos de hemostasia $\mathrm{e}$ fibrinólise joga um papel fundamental no curso natural da reparação dos tecidos ${ }^{23}$. Os resultados obtidos no presente trabalho sugerem que a associação cola de fibrina/ácido tranexâmico tem ação positiva sobre a reparação óssea em ratos.

Estes resultados corroboram aqueles encontrados por Perka et al. ${ }^{6}$ que demonstraram efeito positivo do adesivo fibrínico associado a células do periósteo na formação de tecido ósseo em coelhos após 28 dias de observação. Resultados semelhantes foram também encontrados por Isogai et al. ${ }^{3}$ em camundongos após 12 semanas de observação. Também Abiraman et al. ${ }^{1}$ observaram propriedades osteoindutoras para a combinação de grânulos de hidroxiapatita/vidro bioativo/adesivo fibrínico, Yamada et al. $^{24}$ para a associação $\beta$ TCP/adesivo fibrínico e You et al. ${ }^{25}$ para adição do material ao plasma rico em plaquetas. Hermeto et al. $^{26}$ demonstraram melhor comportamento do adesivo fibrínico Tissucol ${ }^{\circledR}$ em comparação ao plasma rico em plaquetas em situações de enxerto cutâneos de espessura completa em cães.

Ten Hallers et al. ${ }^{11}$ propuseram a estabilização imediata de implantes de titânio por meio de adesivo fibrínico/malha de polipropileno com base nos resultados de seus estudos em tecido conjuntivo subcutâneo de ratos, os quais apontaram ausência do material em 12 semanas de observação. Já Kalebo et al. ${ }^{27}$ avaliaram o efeito da associação de sistema adesivo fibrínico na taxa de reparação ao redor de implantes de titânio cp. Concluiram que a osseointegração foi fortemente influenciada pelo uso do material em associação ao implante. Também Urban et al. ${ }^{28}$ estudaram o efeito do adesivo fibrínico Beriplast ${ }^{\circledR}$ associado à partículas cerâmicas, hidroxiapatita ou fosfato tricálcico na velocidade da osseointegração de implantes. Observaram facilitação no processo de reparação além da incorporação dos materiais particulados ao organismo.

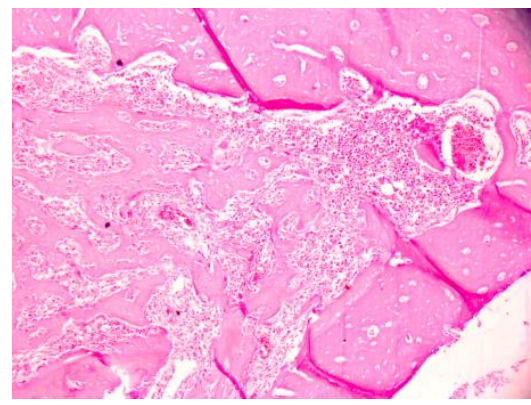

Figura 1: Aspectos histológicos aos 30 dias pós-operatórios de GI (Coloração Hematoxilina/Eosina).

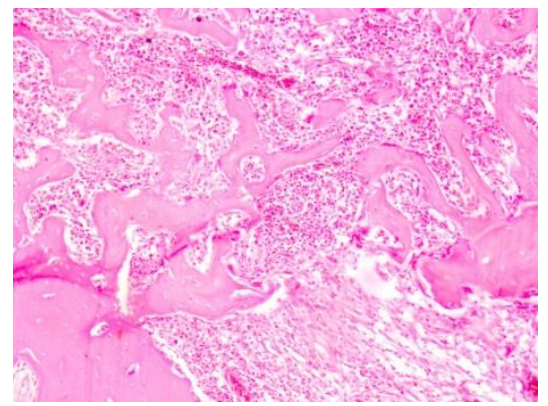

Figura 2: Aspectos histológicos aos 30 dias pós-operatórios de GII (Coloração Hematoxilina/Eosina). 


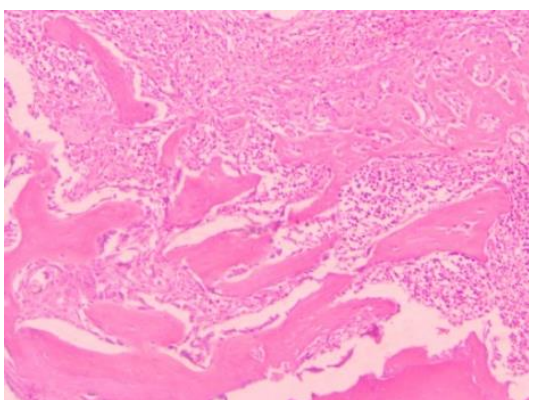

Figura 3: Aspectos histológicos aos 30 dias pós-operatórios de GIII (Coloração Hematoxilina/Eosina).

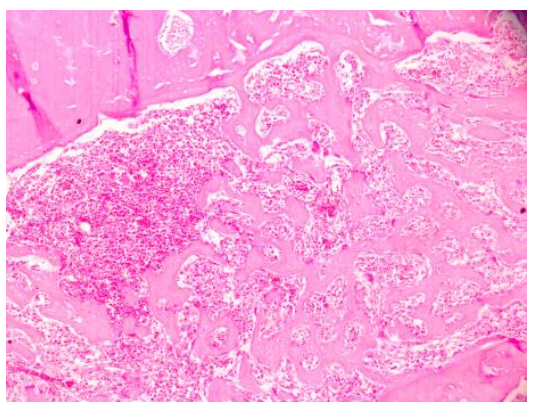

Figura 4: Aspectos histológicos aos 30 dias pós-operatórios de GIV (Coloração Hematoxilina/Eosina).

No presente trabalho a associação da cola de fibrina ao ácido tranexâmico mostrou-se mais favorável à reparação óssea do que o uso isolado do material, por ação dirente do agente antibrinolítico sobre a lise do coágulo de fibrina formado.

De fato, já em 2003 Cox et al. ${ }^{29}$ propunham concentrações inferiores a $300 \mathrm{mM}$ de solução de ácido tranexâmico para coibir lise do coágulo de fibrina formado a partir da reconstituição do adesivvo fibrínico. Furst et al. ${ }^{30}$ lembram que as principais características de fibrina são elevadas resistência à tração, força adesiva, biocompatibilidade e reabsorção. Um grande evento adverso seria a prematura lise de fibrina e hemorragia recorrente, o que pode ser evitado por inibidores de fibrinólise, tais como ácido epsilon aminocaproico e ácido tranexâmico.

Alves-Rezende e Okamoto $^{2}$ observaram controle da fibrinólise provocada pelo estresse quando alvéolos dentários receberam associação Tisscol/ácido epsilon-aminocapróico. Esses resultados foram corroborados por Okamoto e colabs. ${ }^{8}$ em defeitos críticos em tíbias de ratos. Em trabalho posterior Alves-Rezende e colabs. ${ }^{31}$ observaram em ratos favorecimento da geração do coágulo sanguíneo, formação óssea e osseointegração pela ação do ácido tranexâmico, aumentando a capacidade osteogênica dos implantes de titânio CP.

Os resultados obtidos no presente trabalho abrem expectativas para novos estudos utilizando estes materiais em situação de reparação óssea em organismos com alterações sistêmicas metabólicas.

CONCLUSÃO

Com base nos resultados obtidos e metodologia empregada conclui-se que a associação cola de fibrina/ácido tranexâmico teve ação positiva sobre a reparação óssea em ratos.

\section{REFERÊNCIAS}

1. Abiraman S, Varma HK, Umashankar PR, John A. Fibrin glue as an osteoinductive protein in a mouse model. Biomaterials. 2002 ;23:3023-31.

2. Alves-Rezende MC, Okamoto T: Effects of fibrin adhesive material (Tissucol) on alveolar healing in rats under stress. Braz Dent J. 1997; 8(1):13-9.

3. Isogai $\mathrm{N}$, Landis WJ, Mori R, Gotoh $\mathrm{Y}$, Gerstenfeld LC, Upton J, Vacanti JP. Experimental use of fibrin glue to induce sitedirected osteogenesis from cultured periosteal cells. Plast Reconstr Surg. 2000;105(3):953-63.

4. Keating JF, McQueen MM. Substitutes for autologous bone graft in orthopaedic trauma. J Bone Jt Surg Br. 2001; 83: 3-8.

5. Matras H - Fibrin sealant in maxillofacial surgery. Development and indications. A review of the past 12 years. Facial Plast Surg. 1985;2(4):297313.

6. Perka C, Schultz O, Spitzer RS, Lindenhayn K, Burmester GR, Sittinger M. Segmental bone repair by tissue-engineered periosteal cell transplants with bioresorbable fleece and fibrin scaffolds in rabbits. Biomaterials 2000; 21: 114553.

7. Simson J, Crist J, Strehin I, Lu Q, Elisseeff JH . An orthopedic tissue adhesive for targeted delivery of intraoperative biologics. J Orthop Res. 2012 Oct 23. doi: 10.1002/jor.22247.

8. Okamoto T, Alves-Rezende MC, Okamoto AC, Buscariolo IA, Garcia IR Jr: Osseous regeneration in the presence of fibrin adhesive material(Tissucol) and epsilon-aminocaproic acid (EACA). Braz Dent J. 6(2):77-83, 1995

9. Schmitz JP, Hollinger JO. The biology of plateletrich plasma. J Oral Maxillofac Surg. 2001; 59: 1119-21.

10. Shimojo N, Kondo C. Cytotoxicity analysis of a novel titanium alloy in vitro: Adhesion, spreading, and proliferation of human gingival fibroblasts. Bio-Medical Materials and Engineering 17(4): 255-255. 2007

11.ten Hallers EJ, Jansen JA, Marres HA, Rakhorst G, Verkerke GJ. Histological assessment of titanium and polypropylene fiber mesh implantation with and without fibrin tissue glue. J Biomed Mater Res A. 2007 ;80(2):372-80.

12. Okamoto T, Okamoto R, Alves-Rezende MC, Gabrielli MF: Interference of the blood clot on granulation tissue formation after tooth extraction. Histomorphological study in rats. Braz Dent J. 1994; 5(2):85-92.

13.Dahlback B. Blood coagulation and its regulation by anticoagulant pathways: genetic pathogenesis of bleeding and thrombotic diseases. J Intern Med. 
2005,57:209-223.

14. Roberts I, Shakur H, Ker K, Coats T, CRASH-2 trial collaborators. Antifibrinolytic therapy for acute traumatic injury. Cochrane Database Syst Rev. 2011;1:CD004896.

15. Homsen $\mathrm{H}$. Ethanol-insoluble adenine nucleotides in platelets and their possible role in platelet function. Ann N Y Acad Sci. 1972; 27:109-21.

16.Alving BM; Weinstein MJ; Finlaynson JS; Menitone JE, Fratantoni JC: Fibrin sealant: summary of a conference on characteristics and clinical uses. Transfusion 1995; 35:783-90.

17.Luz L, Sankarankutty A, Passos E, Rizoli S, Fraga GP, Nascimento Jr B, Ácido tranexâmico no tratamento da hemorragia no trauma. Rev Col Bras Cir. [periódico na Internet] 2012; 39(1). Disponível em URL: http://www.scielo.br/rcbcMartinowitz U; Saltz R: Fibrin sealant. Curr Opin Hematol. 1996; 3:396402.

18.Dunn CJ, Goa KL. Tranexamic acid: a review of its use in surgery and other indications. Drugs. 1999 Jun;57(6):1005-32.

19. Hoylaerts M, Lijnen HR, Col.len D - Studies on the mechanism of the antifibrinolytic action of tranexamic acid. Biochim Biophys Acta. 1981;18:75-85.

20.Levi M, Cromheecke EM, Jonge et al. Pharmacological strategies to decrease excessive blood loss in cardiac surgery: a meta-analysis of clinically relevant endpoints. Lancet 1999;354:1940-8.

21.Bidolegui F, Arce G, Lugones A, Pereira S, Vindver G. Tranexamic acid reduces blood loss and transfusion in patients undergoing total knee arthroplasty without tourniquet: a prospective randomized controlled trial. Open Orthop J. 2014; 8: 250-4. doi: 10.2174/ 1874325001408010250

22. Scheibe PO. Number of samples-hypothesis testing. Nucl Med Biol. 2008; 35:3-9.

23. Alves Rezende MCR, Kusuda R, Mari GG, Alves LMN, Marinho MLVD, Felipini RC, Okamoto R, Okamoto T, Alves Rezende LGR, Garcia da Silva TC, Alves Claro APR. Efeito do estresse crônico e benzodiazepínicos no reparo ósseo: estudo histológico em ratos. Rev Odontol Araçatuba 2010; 31(1):66-72.

24. Yamada Y, Boo JS, Ozawa R, Nagasaka T, Okazaki Y, Hata K, Ueda M. Bone regeneration following injection of mesenchymal stem cells and fibrin glue with a biodegradable scaffold. J Craniomaxillofac Surg. 2003;31:27-33.

25. You TM, Choi BH, Zhu SJ, Jung JH, Lee SH, Huh JY, Lee HJ, Li J. Platelet-enriched fibrin glue and platelet-rich plasma in the repair of bone defects adjacent to titanium dental implants. Int $\mathbf{J}$ Oral Maxillofac Implants. 2007;22(3):417-22.
26. Hermeto LC, Rossi Rd, Pádua SB, Pontes ER, Santana AE.Comparative study between fibrin glue and platelet rich plasma in dogs skin grafts. Acta Cir Bras. 2012 Nov;27(11):789-94.

27. Kalebo P, Buch P, Albrektsson T. Bone formation rate in osseointegrated titanium implants. Influence of locally applied haemostasis, peripheral blood, autologous bone marrow and fibrin adhesive system (FAS). Scand J Plast Reconstr Surg Hand Surg. 1988; 22 (1):53-60.

28.Urban K, Povysil C, Spelda S. Effect of fibrin on osseointegration of bioactive glass-ceramic materials-experimental study. Acta Chir Orthop Traumatol Cech. 2001; 68(3):168-75.

29. Cox S, Cole M, Mankarious S, Tawil N. Effect of tranexamic acid incorporated in fibrin sealant clots on the cell behavior of neuronal and nonneuronal cells. J Neurosci Res. 2003 Jun 15;72(6):734-46.

30.Furst W, Banerjee A, Redl H. Comparison of structure, strength and cytocompatibility of a fibrin matrix supplemented either with tranexamic acid or aprotinin. J Biomed Mater Res B Appl Biomater. 2007 ;82(1):109-14.

31.Alves-Rezende MCR, Carvalho LMF, Louzada MJQ, Escada ALA, Capellato P, Grandini CR, Alves-Claro APR. Análise morfológica de implantes do sistema Ti-Ta. Influência do ácido tranexâmico. Unopar Científica - Ciências Biológicas e da Saúde - Anais do $48^{\circ}$ Encontro do GBMD 2012; 14:2

\section{CONFLITO DE INTERESSES}

Os autores declaram não haver conflitos de interesse.

\section{AUTOR PARA CORRESPONDENCIA}

Maria Cristina Rosifini Alves Rezende

rezende@foa.unesp.br

Submetido em 30/05/2014

Aceito em 15/08/2014 